\title{
Oestrus Ovis Ophthalmomyiasis in Cyprus
}

\section{Maj C R Winfield}

$M A, B M, M R C P, R A M C$

The Princess Mary's RAF Hospital, Akrotiri

\section{Dr N R H Burgess}

PhD, FRES, MIBiol

Adviser in Entomology to the Ministry of Defence

Royal Army Medical College, Millbank

\section{Introduction}

Human ophthalmomyiasis due to infestation with the larvae of the sheep nasal bot fly Oestrus ovis has been known for 70 years $^{1}$ and the parasite is widely distributed in the Mediterranean, Russia, India, South Africa, Canada and the USA. There has been no report of cases from Cyprus in spite of many cases occurring each year among the local community. Three cases of Oestrus ovis ophthalmomyiasis in Service personnel were treated at the RAF Hospital Akrotiri during the summer of 1982 and the details of these cases are reported here.

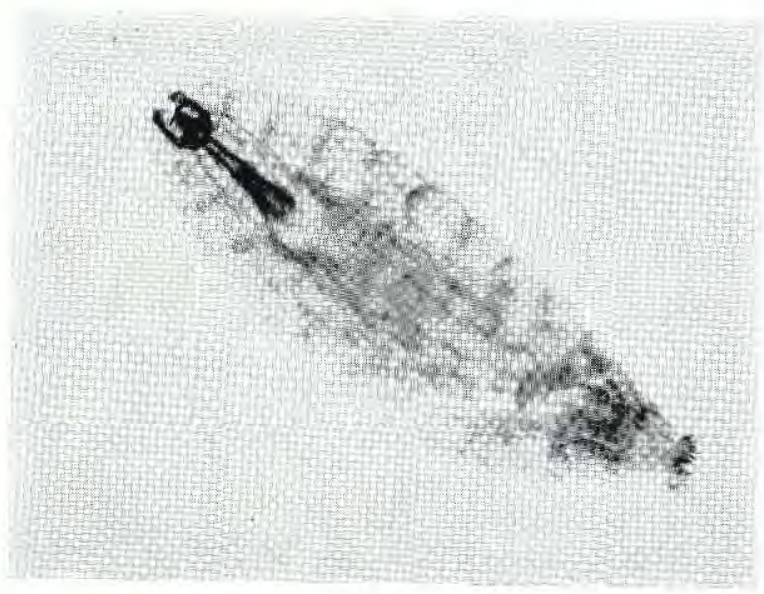

Fig. 1 First instar larva of Oestrus ovis. (magnification $\times 130$ )

\section{Patients and Treatment}

From July to September three previously healthy young male patients, all residing at RAF Akrotiri, reported the sudden onset of intense superficial monocular irritation, developing shortly after fly entry in one, but not associated with this in the others. The treatment in two cases consisted of manual removal under local anaesthesia using sterile swab on a stick, and repeated saline irrigation in the third case. The diagnosis was made by micro scopic examination of the removed parasites and identification from published literature ${ }^{2}$. A photo graph of one of the extracted larvae is shown (Fige 1). All three patients received prophylactic topieat antibiotics; two made a complete recovery but third developed an acute conjunctivitis after 12 daȳs The details of the patients and their symptoms recorded in Table $\mathrm{I}$.

\section{Discussion}

As its name suggests, the sheep nasal bot Oestrus ovis does not rely on man as a princige host for the intermediate larval stages of its cycle. The fly usually deposits the freshly hatc $1.3 \mathrm{~mm}$ long, first instar larva into the eyes o⿸尸 nostrils of sheep, goats and occasionally dogs og antelopes. The larva may migrate from this site of initial deposition into the sinuses, the throat, the trachea and rarely across the bronchial wall, whiclo은 has fatal results. The infestation does not produce a high mortality among infected animals unless thes are young or heavily infested. The maturing larv which is $3.5-12 \mathrm{~mm}$ in length develops in the hos? animal. When fully developed it leaves the host and pupates within 1-5 days on the ground, the aduls fly emerging some 28 days later. Man is an unsuit able host for the larva and development does no progress beyond the first instar, death usually occuro ring within a few days. The larvae are usuall? deposited in the eye but also in the nose, throat an 8 external ear and, unlike the larvae of the cattle bop fly, Hypoderma species, they do not penetrate tog deeper structures. It is thought that man becomes infested in areas where the ratio of the human to. the sheep population is fairly high, the gravid flien being unable to find a suitable animal host an\& deposit on man in desperation.

This situation may well exist in Akrotiri as apN్E 
proximately 2,000 sheep and goats from the villa have an unofficial grazing concession within the boundaries of the Station and 3,400 Servicemen a $\overline{\alpha d}$ their dependants live in the same area.

In areas where human ophthalmomyiasis has been reported there is a seasonal incidence and in Irọq for example the peak incidence of cases occurs from March to June and September to November. P色sumably pupae do not survive the hot and dry conditions of the intervening months. Continuation the species to the following year is ensured By survival of the first instar larvae in the nasal caviby of the host during the winter months.

Although there have been no case reports of human Oestrus ovis ophthalmomyiasis from Cyprus, the condition is in fact quite common in the loçal population. One ophthalmic surgeon treats up toga hundred cases a year ${ }^{4}$ by removing the parasite wien fine forceps under the magnification of slit lamp

Manual removal of the parasite is difficult because of its small size and the adhesion provided its mouth hooks, but in the apparent absence of topical parasiticidal agent harmless to the dit remains the usual treatment and the method usefg in these three reported cases. Purulent conjunctivitis may occur after infestation or parasite removal 7 and treatment with a topical antibiotic is advisable.

Ophthalmomyiasis is not a common condition it should be considered in the differential diagno of a painful red eye occurring in an appropatyte part of the world, particularly if the patientodescribes a sensation of sub-palpebral movement.

\section{Acknowledgements}

We are grateful to Sqn Ldr G A Morris and $\underset{B}{\mathbb{B}}$ $\mathrm{R}$ Bergman for permission to report cases in the care.

\section{REFERENCES}

1 Al-Dabagh, $M$ et al (1980). A second record frôn Iraq of human myiasis caused by larvae of the sheep bot fly Oestrus ovis L. Anns. Trop Med \& Par. 1980; 74: 873-877.

2 SMART, J, JoRdan, $K$ and WhitTICK, R J. Insects $\frac{D}{\text { of }}$ Medical Importance, 3rd Edition, 1956.

3 ZuMPT, F. Myiasis in Man and Animals in the Offd World. Butterworths, London; 1965.

4 Vorkas, A P. Personal communication. 